\title{
Pretreatment of rice straw with combined process using dilute sulfuric acid and aqueous ammonia
}

\author{
Sung Bong Kim¹, Sang Jun Lee', Ju Hun Lee', You Ree Jung', Laxmi Prasad Thapa', Jun Seok Kim², \\ Youngsoon $\mathrm{Um}^{3}$, Chulhwan Park ${ }^{4^{*}}$ and Seung Wook Kim ${ }^{1^{*}}$
}

\begin{abstract}
Background: Use of lignocellulosic biomass has received attention lately because it can be converted into various versatile chemical compounds by biological processes. In this study, a two-step pretreatment with dilute sulfuric acid and aqueous ammonia was performed efficiently on rice straw to obtain fermentable sugar. The soaking in aqueous ammonia process was also optimized by a statistical method.

Results: Response surface methodology was employed. The determination coefficient $\left(R^{2}\right)$ value was found to be 0.9607 and the coefficient of variance was 6.77. The optimal pretreatment conditions were a temperature of $42.75^{\circ} \mathrm{C}$, an aqueous ammonia concentration of $20.93 \%$, and a reaction time of $48 \mathrm{~h}$. The optimal enzyme concentration for saccharification was 30 filter paper units. The crystallinity index was approximately $60.23 \%$ and the Fourier transform infrared results showed the distinct peaks of glucan. Ethanol production using Saccharomyces cerevisiae K35 was performed to verify whether the glucose saccharified from rice straw was fermentable.
\end{abstract}

Conclusions: The combined pretreatment using dilute sulfuric acid and aqueous ammonia on rice straw efficiently yielded fermentable sugar and achieved almost the same crystallinity index as that of a-cellulose.

Keywords: Rice straw, Pretreatment, Soaking aqueous ammonia, Dilute acid pretreatment, Response surface methodology

\section{Background}

Biomass pretreatments are key steps in the low-cost bioconversion of cellulosic biomass to sugar because of the rigid and hard-to-degrade structure of the biomass cell walls. Pretreatments are used to release cellulose from amorphous lignin and hemicellulose. Chemical pretreatments using acid and alkali reagents have been widely studied because of their simplicity and efficient performance.

Acid pretreatments hydrolyze plant cell walls, especially their hemicellulose component. $\mathrm{H}_{2} \mathrm{SO}_{4}, \mathrm{HNO}_{3}$, and $\mathrm{HCl}$ are usually used for acid pretreatments in dilute and acidic states [1-4]. The solubilized hemicellulose can be converted to xylose, a monomer, in acidic media, and the xylose can then be overdegraded in a strongly acidic environment

\footnotetext{
* Correspondence: chpark@kw.ac.kr; kimsw@korea.ac.kr

${ }^{4}$ Department of Chemical Engineering, Kwangwoon University, Seoul 139-701, South Korea

'Department of Chemical and Biological Engineering, Korea University, Seoul 136-701, South Korea

Full list of author information is available at the end of the article
}

$[5,6]$. Though glucose and xylose can biologically yield versatile building block products of various biochemicals, they can also be overdegraded and converted to by-products such as furfural and hydroxymethylfurfural (HMF), respectively [3,7]. Therefore, in order to achieve selective hydrolysis using an acid reagent, an appropriate acid concentration, reaction temperature, and other critical factors must be experimentally determined.

Alkaline pretreatments have also been extensively studied for modifying cell walls. During such pretreatments, solvation and saponification reactions take place [3]. As a result, the biomass swells, and access to its inner space by saccharification enzymes is enhanced $[3,8]$. Also, alkali pretreatments selectively remove lignin portion mainly. Xylan and lignin support the cellulose backbone that includes the biomass cell wall $[1,3]$. Though ammonia has been widely used in alkali pretreatments, its use leads to many environmental problems because of which recovery and recycling processes must also be used along with this pretreatment. $\mathrm{NaOH}$ and $\mathrm{KOH}$ have also been evaluated for use in 
alkali pretreatments because they are cheaper than ammonia $[9,10]$.

In our previous work, rice straw was pretreated with dilute sulfuric acid and pretreatment using the compounds was analyzed. In addition, to avoid the overdegradation of biomass, the pretreatment was optimized using a statistical model and a computer program [11]. As xylose is obtained from hemicellulose, lignin can also be converted into useful compounds such as organic solvents, aromatic compounds, and fuel additives by chemical and biological methods. Removal of hemicellulose and lignin could dramatically improve enzyme digestibility by enhancing the enzyme accessibility to cellulose. The pretreatment with dilute sulfuric acid followed by aqueous ammonia would then be needed for efficient saccharification and lignin isolation.

In this study, rice straw was pretreated with dilute sulfuric acid under the conditions previously described [11]. The rice straw that had been subjected to dilute-acid pretreatments to remove a large portion of amorphous hemicellulose was pretreated again with aqueous ammonia to remove lignin. The process of soaking in aqueous ammonia (SAA) was optimized, and pretreatment factors were analyzed using a statistical method and model. After statistical analysis, X-ray diffractometer (XRD) was utilized to measure the crystallinity index $(\mathrm{CrI})$, and Fourier transform infrared (FTIR) analysis was performed to investigate the molecule structure of rice straw. The rice straw, which was copretreated with dilute acid and aqueous ammonia, was saccharified using saccharification enzymes. Figure 1 shows the schematic depiction of the processes used in this study.

\section{Results and discussion}

\section{Response surface methodology analysis}

Rice straw was pretreated with dilute sulfuric acid under previously optimized conditions: $142^{\circ} \mathrm{C}$ temperature, $1.21 \%$ concentration of sulfuric acid, and $11.6 \mathrm{~min}$ reaction time [11]. After the pretreatment, the solid portion comprising the treated rice straw and the liquid portion of hydrolysates containing the solubilized xylose was separated by filtration. The solids were washed with distilled water and subsequently treated with aqueous ammonia. The pretreatment with aqueous ammonia was optimized using a statistical method.

The factors affecting the statistical analysis were temperature, concentration of aqueous ammonia, and reaction time that were determined from fundamental experiments. In the pretreatment process with aqueous ammonia, the aforementioned three factors strongly and directly affected either the productivity of sugar or the energy cost of the process. Fundamental experiments to determine the range of each of these factors were performed before the experiment using a statistical model. The temperature range, aqueous ammonia concentration, and reaction time were employed as described in the "Methods" section. The amount of glucose recovered from saccharification after SAA for each designed condition was used as the data for the statistical analysis.

Central composite design (CCD) was used to investigate the effects of different factors on the rice straw pretreatment. Design Expert ${ }^{\oplus} 6.0$ software was employed to obtain the analysis of variance (ANOVA), regression

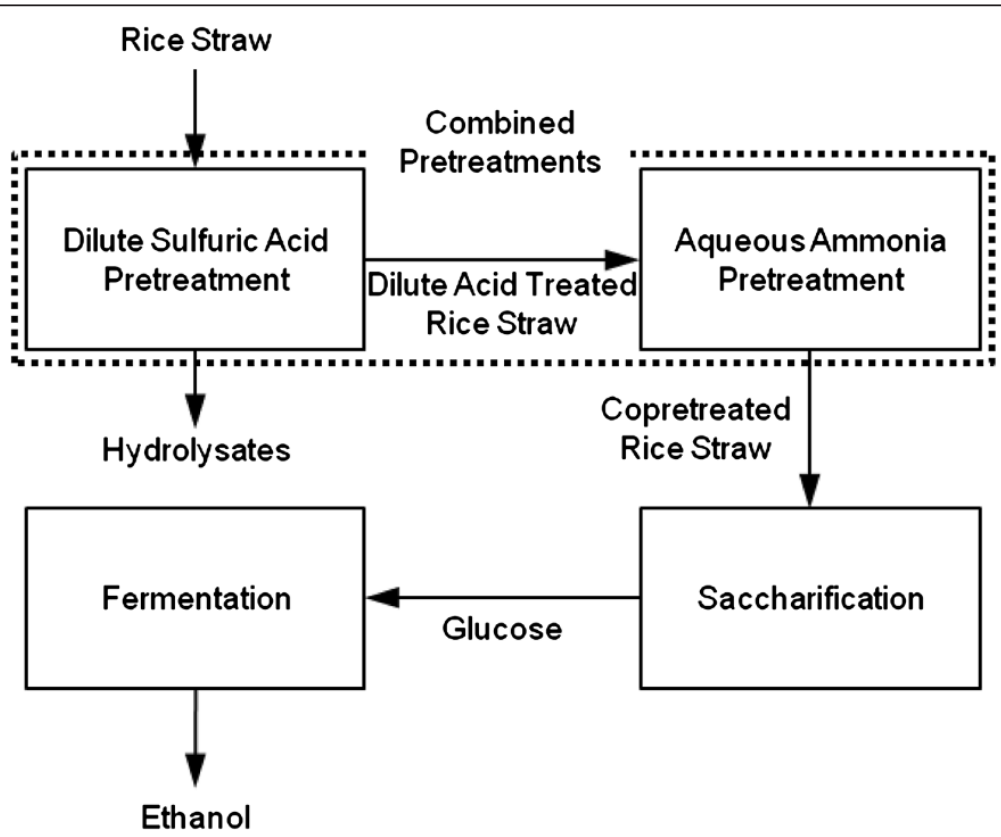

Figure 1 Schematic depiction of processes used in this study. 
Table 1 Results of analysis of variance (ANOVA)

\begin{tabular}{llllll}
\hline Source & DF & Sum of squares & Mean square & F value & 27.15 \\
\hline Model & 9 & 5103.98 & 567.11 & \\
Error & 10 & 208.278 & 20.82 & \\
Corrected total & 19 & 5314.738 & & \\
\hline
\end{tabular}

$C V=6.77, R^{2}=0.9607$.

coefficients, and polynomial regression equation from the data of the CCD experiment. Table 1 shows the results of ANOVA of the CCD model.

The coefficient of variation $(\mathrm{CV})$ is the degree of precision with which experiments are similar. In the current study, a CV of $6.77 \%$ was obtained. The CV is a function of the standard deviation and standardizes the scale of data. In general, a lower $\mathrm{CV}$ indicates that the factors are highly reliable during the optimization. The determination coefficient $\left(R^{2}\right)$ was 0.9607 (96.07\%), and a higher determination coefficient indicated a higher reliability regarding the relationship between the observed experimental data and designed predictions. A high Fvalue of 27.15, indicating a high efficiency of the factors, was obtained (Table 1). Furthermore, P-value, which is important to understanding the pattern of mutual interactions between the variables, was lower than 0.0001 (Table 1). Usually, when P-value is lower than 0.05, the factors are considerably varied and statistically significant. Table 2 shows the statistical analysis of the factors. The following polynomial equation was obtained using multiple regression analysis. The most effective factor was ammonia concentration, which had an F-value of 136.73; the temperature was also found to be critical.

$$
\begin{aligned}
Y= & 78.14-5.81 X_{1}+14.46 X_{2} \\
& +3.51 X_{3}-3.96 X_{11}-9.06 X_{22}-2.50 X_{33} \\
& +1.20 X_{12}-1.65 X_{13}+5.48 X_{23}
\end{aligned}
$$

Table 2 Statistical analysis of factors

\begin{tabular}{ccccc}
\hline Source & DF & Mean square & F value & $\operatorname{Pr}>F$ \\
\hline $\mathbf{X}_{\mathbf{1}}$ & 1 & 460.91 & 22.07 & 0.0008 \\
$\mathbf{X}_{\mathbf{2}}$ & 1 & 2855.64 & 136.74 & $<.0001$ \\
$\mathbf{X}_{\mathbf{3}}$ & 1 & 169.05 & 8.06 & 0.0176 \\
$\mathbf{X}_{\mathbf{1 1}}$ & 1 & 124.56 & 10.82 & 0.0082 \\
$\mathbf{X}_{\mathbf{2 2}}$ & 1 & 1130.13 & 56.67 & $<.0001$ \\
$\mathbf{X}_{\mathbf{3 3}}$ & 1 & 90.10 & 4.32 & 0.0644 \\
$\mathbf{X}_{\mathbf{1 2}}$ & 1 & 11.23 & 0.55 & 0.4761 \\
$\mathbf{X}_{\mathbf{1 3}}$ & 1 & 22.11 & 1.04 & 0.3309 \\
$\mathbf{X}_{\mathbf{2 3}}$ & 1 & 2241.12 & 11.50 & 0.0069 \\
\hline $\mathbf{X}_{\mathbf{1}}: \mathbf{T n}$ & 1 & & &
\end{tabular}

$\mathrm{X}_{1}$ : Temperature.

$X_{2}$ : Concentration of aqueous ammonia.

$\mathrm{X}_{3}$ : Reaction time. where $X_{1}$ is a coded value of the temperature, $X_{2}$ is a coded value of the ammonia concentration, and $X_{3}$ is a coded value of the reaction time. Once the derived equation (PDE) was solved, three contour plots and a threedimensional mesh were obtained (Figure 2). Figure 2(A) is a plot of $X_{1}$ vs. $X_{2}$, Figure 2(B) depicts $X_{2}$ vs. $X_{3}$, and Figure $2(\mathrm{C})$ is a plot of $X_{1}$ vs. $X_{3}$. The graphs of threedimensional mesh with each contour plot show the effect of each factor and the approximate optimal point. The shapes of the response surfaces indicated the nature and extent of the interactions between the different factors $[12,13]$. In nature, a high temperature and a long reaction time might not decrease the enzyme digestibility. However, the three-dimensional shape decreased when these aforementioned factors increased, which affected the regression of the design of experiment (DOE) results. However, the regression surfaces indicated that as these factors increased, conversion of glucose increased, and that the axis of the reaction time factor was not much different than that of the other factors. In addition, at the appropriate aqueous ammonia concentration and temperature, the effect of the reaction time was not significant after $12 \mathrm{~h}$. Also, the perturbation in the conversions of $X_{2}$ was larger than that of others, and the difference of $X_{2}$ in range was based on the F-values.

\section{Optimization, confirmation, and enzyme loading test}

The optimal coded values, determined by response surface methodology (RSM), were -0.8625 for temperature $\left(X_{1}\right), 0.7412$ for aqueous ammonia concentration $\left(X_{2}\right)$, and 0 for reaction time $\left(X_{3}\right)$, whereas the real values were $48.75^{\circ} \mathrm{C}, 20.93 \%$, and $48 \mathrm{~h}$, respectively. In the statistical analysis and optimization, wherein the results were analyzed based on the numerical regression level, the optimal reaction time was approximately $79 \mathrm{~h}$. Though the process lasted for over $80 \mathrm{~h}$, the yield was not notable compared to that obtained with a reaction time of $48 \mathrm{~h}$.

Some portion of lignin was removed and the biomass structure was swollen; however, maximum glucose recovery or initial reaction rate could not be enhanced. In addition, there was no significant improvement in the initial reaction rate and maximum glucose conversion even when more than $50 \%$ of the lignin was solubilized. Reaction time factors were closely associated with the energy cost, and the SAA was carried out for 24-48 h. Design Expert ${ }^{\odot}$ provided the adjustment of the optimal 

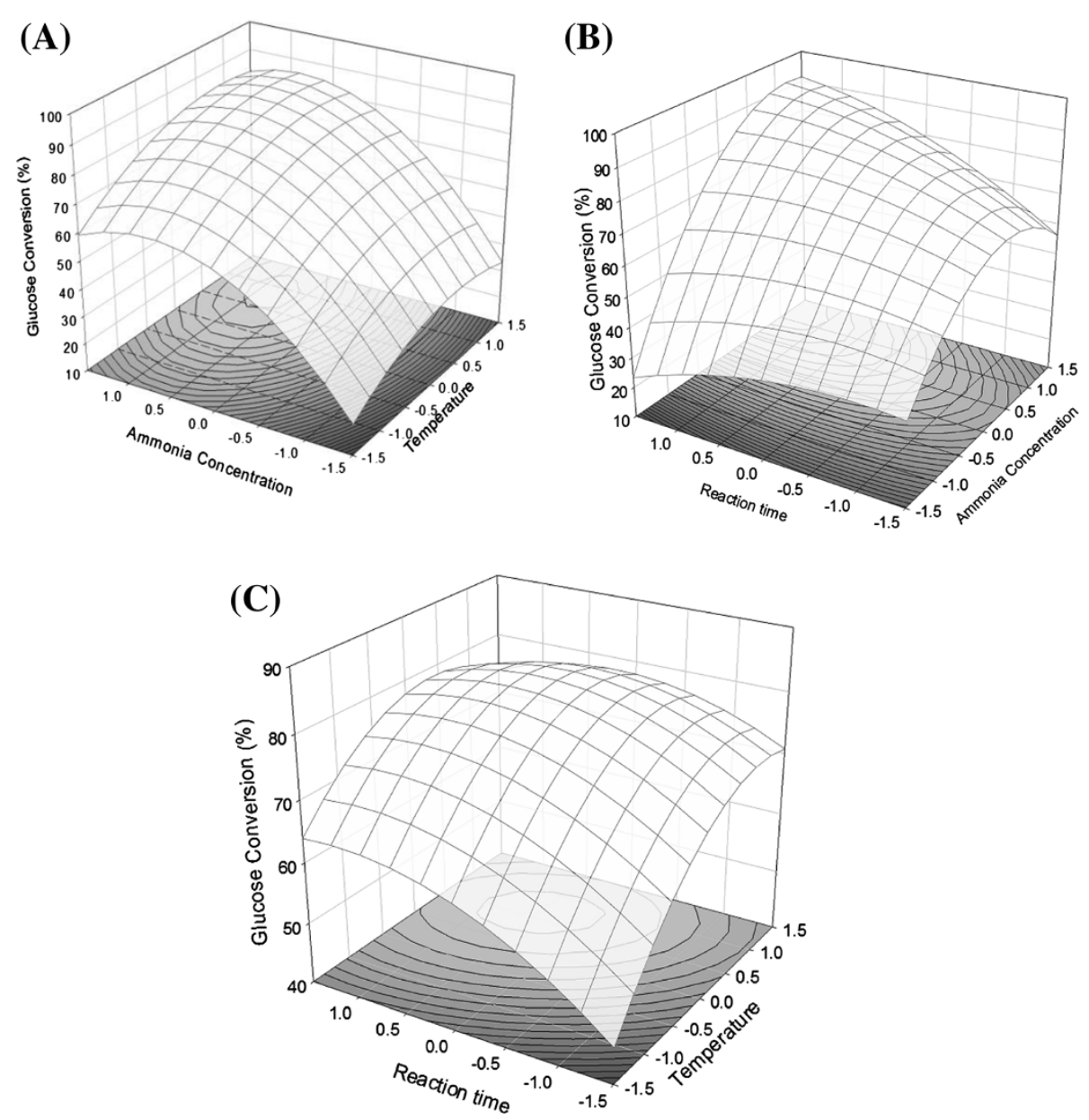

Figure 2 Response surface plots of effect of each factor on glucose yield from soaking in aqueous ammonia process. (A): Effects of temperature and aqueous ammonia concentration; (B): Effects of aqueous ammonia concentration and reaction time; (C): Effects of temperature and reaction time.

result so as to be suitable for the real process, and the reaction time was limited to less than the reaction time of $48 \mathrm{~h}$. Thus, the analysis conditions were minimized with regard to temperature and $48 \mathrm{~h}$ over a forced maximum range, and optimum of $48 \mathrm{~h}$ were derived by the function of statistical program. After the pretreatment with the derived optimum conditions, solid analysis of rice straw was performed to confirm the change in the rice straw composition of each sample. All experiments were conducted in triplicate. Table 3 lists the results of the comparison of the compositions of raw rice straw
(RR), dilute-acid-pretreated rice straw (DR), and dilute acid and aqueous ammonia combined pretreated rice straw (DAR). The RR had approximately $39.34 \%$ glucan. The glucan portion was, in practice, the quantity of theoretical maximum. In the case of DR, the glucan portion increased to $68.38 \%$ because most of XMG (xylan, mannan and galactan) was removed. When a SAA pretreatment was performed on the DR, approximately $79.75 \%$ glucan was observed because of the removal of xylan and lignin, two major structural inhibitors. The determined theoretical maximum quantity of glucose for RR

Table 3 Effect of pretreatments on rice straw composition

\begin{tabular}{lccc}
\hline & Raw rice straw (RR) & Dilute acid pretreated rice straw (DR) & Combined pretreated rice straw (DAR) \\
\hline Glucan & $39.34 \pm 2.35 \%(\mathrm{TM}=7.86 \mathrm{~g} / \mathrm{L})$ & $68.38 \pm 1.71 \%(\mathrm{TM}=13.67 \mathrm{~g} / \mathrm{L})$ & $79.75 \pm 3.87 \%(\mathrm{TM}=15.95 \mathrm{~g} / \mathrm{L})$ \\
XMG & $28.46 \pm 2.07 \%$ & $10.15 \pm 1.05 \%$ & $10.87 \pm 1.56 \%$ \\
Others & $30.2 \pm 1.68 \%$ & $21.47 \pm 1.52 \%$ & $9.38 \pm 1.01 \%$ \\
\hline
\end{tabular}

※.MG: xylan, mannan and galactan.

※Others: containing lignin and ash.

※TM: theoretical maximum. 
was $7.86 \mathrm{~g} / \mathrm{L}$, for DR was $13.67 \mathrm{~g} / \mathrm{L}$, and for DAR was $15.95 \mathrm{~g} / \mathrm{L}$. The derived optima were confirmed by saccharification, and when these conditions were used for the pretreatment, $78.04 \%$ (approximately $12.44 \mathrm{~g} / \mathrm{L}$ ) of glucose was obtained, similar to those observed with a reaction time of $79 \mathrm{~h}(78.42 \%, 12.50 \mathrm{~g} / \mathrm{L})$. This similarity was expected because of the low F-value of the reaction time factor in the statistical analysis. The predicted maximum value for the saccharified glucose was approximately $75.16 \%$ [14].

After two steps of the pretreatment with dilute acid and aqueous ammonia, saccharification with enzyme loading test was performed on 5-60 filter paper units
(FPU) of Celluclast (cellulase) and 1.7-20 cellobiase units (CBU) of Novozyme 188 ( $\beta$-glucosidase). Figure 3(A) shows the results of enzyme-loading test. When 30 FPU Cellulase and $10 \mathrm{CBU} \beta$-glucosidase were utilized for saccharification, the value of glucose conversion obtained was approximately $80.12 \%$ of the theoretical maximum at $12 \mathrm{~h}$. After $72 \mathrm{~h}$ reaction time, $86.43 \%$ glucose was recovered, and the initial reaction rate (at $2 \mathrm{~h}$ ) was $1.384 \times 10^{-3} \mathrm{~g} / \mathrm{L} \cdot \mathrm{s}$. Approximately $84.71 \%$ glucose was obtained after $12 \mathrm{~h}$ when $60 \mathrm{FPU}$ with $20 \mathrm{CBU}$ were used, and the initial reaction rate was $1.418 \times 10^{-3} \mathrm{~g} / \mathrm{L} \cdot \mathrm{s}$. The maximum conversion after $72 \mathrm{~h}$ and the initial reaction rate (at $2 \mathrm{~h}$ ) were similar at $30 \mathrm{FPU}$ and $60 \mathrm{FPU}$,

(A)

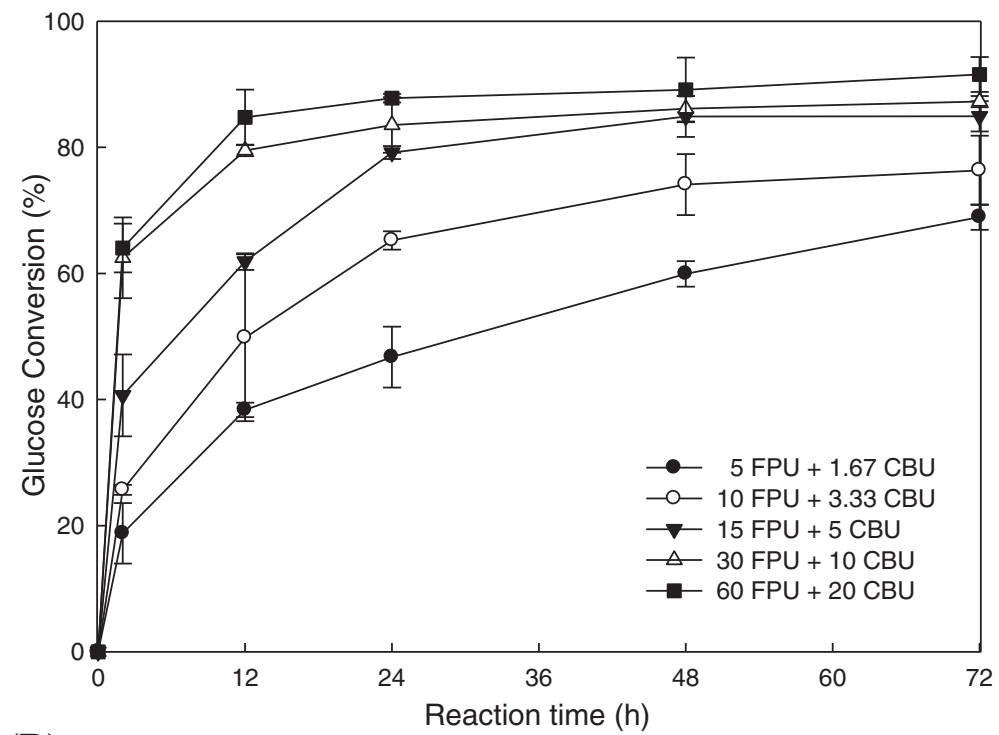

(B)

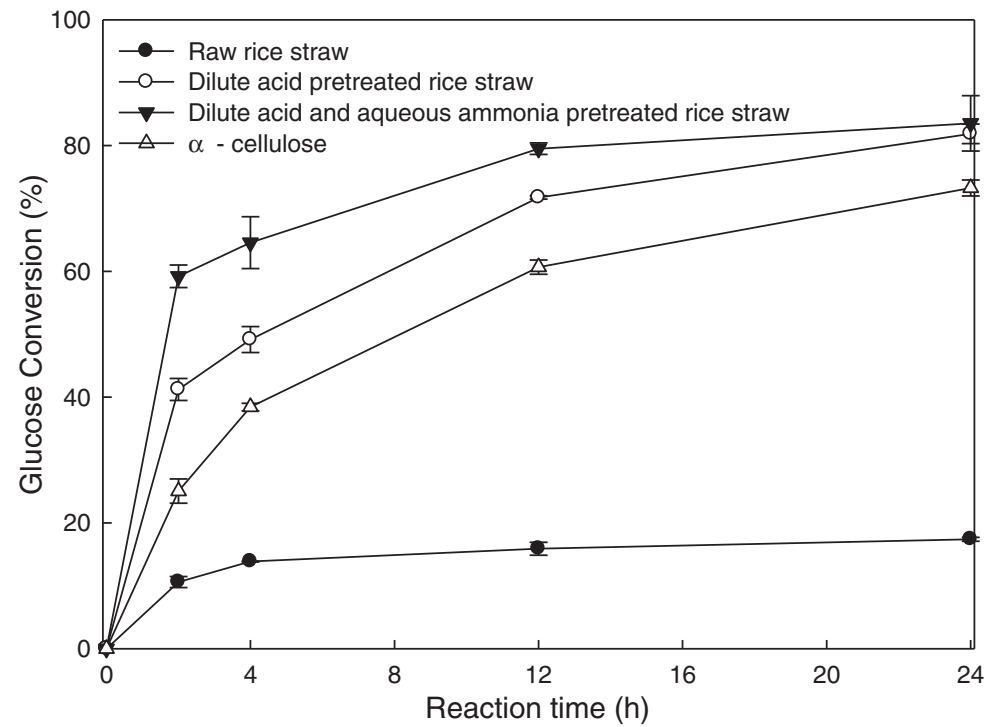

Figure 3 Saccharification of pretreated and untreated rice straw. (A): Enzyme loading test of DAR; (B): Comparison of RR, DR, DAR, and a-cellulose in enzyme media of 30 FPU Celluclast $1.5 \mathrm{~L}$ and 10 CBU Novozyme 188. 
but the conversion of glucose was not notable with regard to the maximum or initial reaction rate below 30 FPU. Thus, $30 \mathrm{FPU}$ with $10 \mathrm{CBU}$ was determined to be the appropriate enzyme-loading dosage.

Figure 3(B) shows the comparison of the RR, DR and DAR in saccharification using $30 \mathrm{FPU}$ of Celluclast and $10 \mathrm{CBU}$ of Novozyme 188. When dilute sulfuric acid was employed, initial reaction rate was $7.657 \times 10^{-4} \mathrm{~g} / \mathrm{L} \cdot \mathrm{s}$, which was 6.61 times higher than that of the RR $\left(1.158 \times 10^{-4} \mathrm{~g} / \mathrm{L} \cdot \mathrm{s}\right)$. When pretreatments with dilute sulfuric acid and aqueous ammonia were employed, the initial reaction rate was approximately 11.94-fold higher $\left(1.384 \times 10^{-3} \mathrm{~g} / \mathrm{L} \cdot \mathrm{s}\right)$ than the values obtained for $\mathrm{RR}$. Thus, pretreatments with dilute acid and aqueous ammonia were more effective compared to a one-step pretreatment. Ko et al. treated rice straw using aqueous ammonia and obtained $71.1 \%$ glucose conversion [15]. Chen et al. suggested the use of a dilute acid and steam explosion to treat rice straw, and as a result, glucose conversion of approximately $85 \%$ was obtained [16]. The results of the current study were notable compared to the earlier results. Also, Kim et al. reported a two-stage pretreatment of rice straw using aqueous ammonia and dilute acid in a facilitating apparatus and obtained approximately $89 \%$ glucose conversion [17]. Our study employed SAA under atmospheric conditions and yielded results that were significant within the statistical error range.

\section{Analysis of pretreated biomass}

Chemically treated rice straw was analyzed by XRD and FTIR to investigate the change in rice straw before and after the pretreatment.

The CrI was measured using XRD, where an increase in the $\mathrm{CrI}$ represented enhanced enzyme digestibility $[8,18,19]$. Figure $4(\mathrm{~A})$ shows the results of the XRD analysis. The crystalline portion was $22^{\circ}$ and the amorphous portion was $18^{\circ}$. Spectrum-3 corresponded to RR and its CrI was $35.42 \%$. The CrI of DR (spectrum-4) was approximately $46.68 \%$, which was higher than that of the RR. When rice straw was sequentially treated under the optimized conditions of dilute acid and aqueous ammonia (DAR, spectrum-2), CrI increased to $60.23 \%$, which was similar to that of $\alpha$-cellulose $(60.92 \%$, spectrum-1), which is pure cellulose composed of crystalline and amorphous cellulose. In the combined pretreatment with a dilute acid and an alkali, a significant portion of the amorphous material, such as xylan and lignin, was removed. At the same time, either a small portion of the crystalline material, such as glucan, was removed or the crystalline structure was broken by swelling or hydrolysis. Thus, the portion of the exposed crystalline structure could be increased compared to either RR or DR.

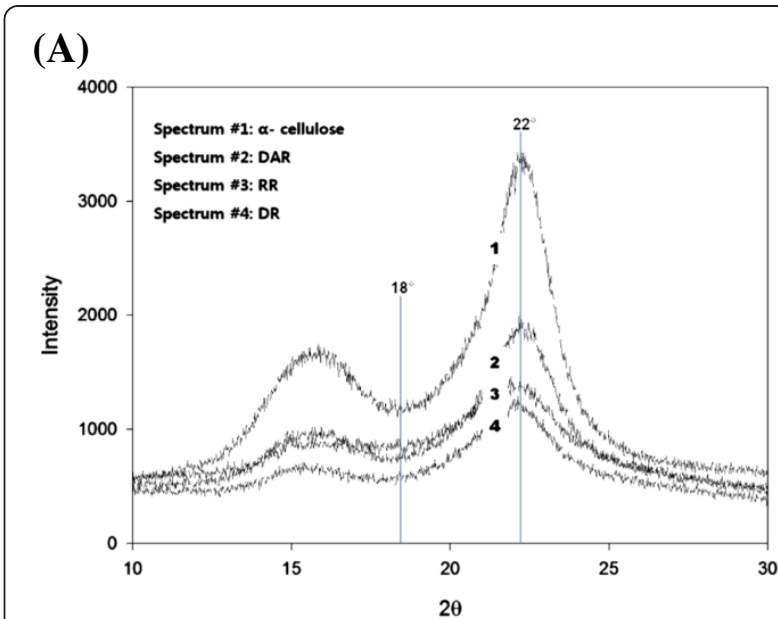

(B)

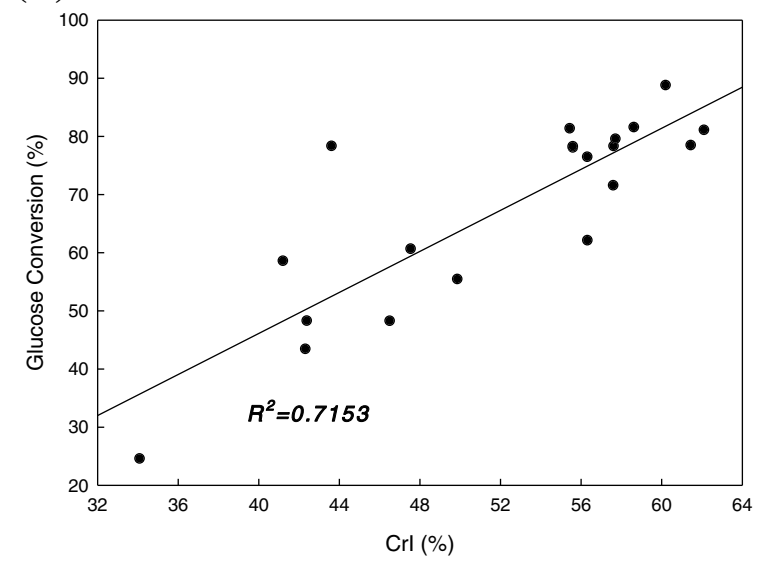

(C)

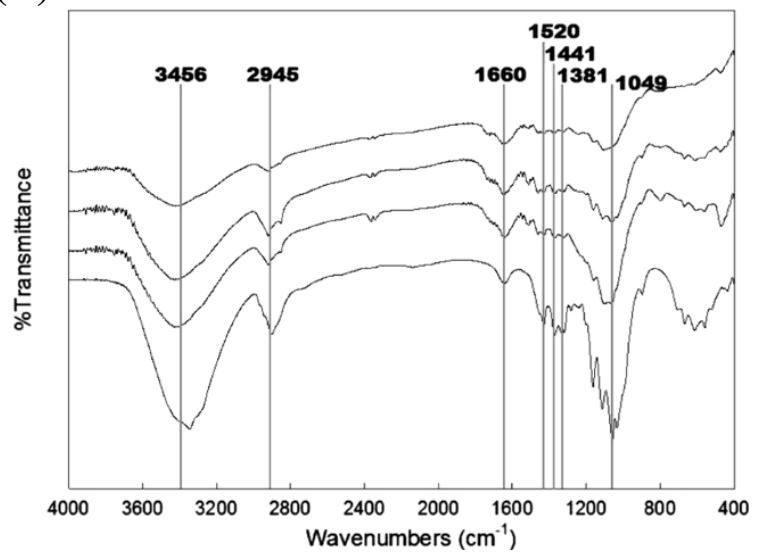

Figure 4 Instrumental analysis of biomass before and after pretreatment. (A): Results of XRD. Crystalline region at $2 \theta=22^{\circ}$ and amorphous portion at $2 \theta=18^{\circ}$ were used to calculate crystallinity index (Crl); (B): Relationship of $\mathrm{Crl}$ with enzyme digestibility; (C): Results of FTIR spectroscopy.

Although the CrI values of DAR as well as those of $\alpha$-cellulose were similar, the actual states of the micro structure could be different. 
Moreover, correlation of glucose conversion with the CrI values of $R R, D R$, and DAR were analyzed by the linear regression of the plotted data. Figure 4(B) shows the results of regression between the $\mathrm{CrI}$ and glucose conversion. The relation was approximately proportional, which meant that an increase in the $\mathrm{CrI}$ corresponded to the removal of barriers for enzymatic accessibility and a relatively high $\mathrm{CrI}$ indicated high enzyme digestibility. The value of $R^{2}$ was 0.7153 . Many researchers have examined the relationship between the CrI and enzyme digestibility. Fan et al. (1987) studied this relationship and reported similar results [19]. Kim et al. (2003) studied the effect of ammonia pretreatments on corn stover and found that an increase in CrI roughly corresponded to an increase in enzyme digestibility [20].

Figure 4(C) shows the results of the FTIR analysis that was performed to prove that the crystalline portion was cellulose. Sun et al. (2002) performed such analysis and reported that the biomass structure was composed of $\beta$ glucosidic bonds and carbon hydrates [21]. The control spectrum is no. 1 , which corresponded to $\alpha$-cellulose. The band intensities provided the following information: $3456 \mathrm{~cm}^{-1}$ indicated an O-H group, $2945 \mathrm{~cm}^{-1}$ indicated a $\mathrm{CH}$ group, $1381 \mathrm{~cm}^{-1}$ indicated $\mathrm{C}-\mathrm{CH}_{3}$ group, $1660 \mathrm{~cm}^{-1}$ indicated a $\beta$-glucosidic bond between the sugar monomers, and $1520 \mathrm{~cm}^{-1}$ and $1441 \mathrm{~cm}^{-1}$ indicated an aromatic ring. Spectrum- 4 is RR, spectrum-3 is DR, and spectrum-2 is DAR. The peaks in spectrum- 4 were blunt and not as sharp as those in spectrum-1, while those in spectrum-3 were less blunt than those in spectrum 4 . In contrast, the peaks in spectrum-2 were sharper and clearer. These results indicated that the material became purer after the pretreatment. Thus, these band intensities showed the specific functions and bonds that corresponded to the cellulose structure. By using these pretreatment steps, barriers to enzyme accessibility were removed from the structure of the rice straw, and consequently, the cellulose portion was exposed [20,21].

\section{Fermentation of glucose}

Fermentation was conducted using glucose produced by saccharification. Then, enzyme deactivation was performed by boiling, followed by centrifugation to remove the solids. The supernatants were collected and concentrated using an evaporator. The glucose concentration was increased to $62 \mathrm{~g} / \mathrm{L}$ (approx. 6\%), which was over four times the concentration of the initial glucose solution recovered from the DAR. The glucose solution was diluted by the same amount of nutrients solution, and the initial glucose concentration before fermentation was approximately $31 \mathrm{~g} / \mathrm{L}$. The fermentation was carried out with Saccharomyces cerevisiae $\mathrm{K} 35$ at $30^{\circ} \mathrm{C}$ and $200 \mathrm{rpm}$ for $24 \mathrm{~h}$. Control fermentation was performed using pure glucose of reagent quality under the aforementioned conditions of fermentation. The fermentation profiles are shown in Figure 5. Over $90 \%$ of glucose was consumed after $6 \mathrm{~h}$, and ethanol production reached approximately $83.25 \%$. The fermentation was independently conducted five times and the deviation was relatively higher than control fermentation, probably because of the effect of inhibitors. This means that the recovered glucose was fermentable but an additional process was needed to remove the inhibitors needed before fermentation. Lee et al. have reported the effects of the inhibitory compounds, particularly on the ethanol production [22,23].

Also, trace amounts of the pretreatment reagent could have remained in the fermentation media. Ammonia is a strong and effective reagent for alkali pretreatments, but it is environmentally harmful and could affect the growth of microorganism. Thus, it needs to be recovered and recycled. In practice, SAA is a batch process. The current work deals with the optimization of the pretreatment conditions and could be utilized in processes involving the recycling and percolation of chemical reagents.

\section{Conclusion}

Rice straw was pretreated in a two-step sequential process using dilute sulfuric acid and aqueous ammonia. Statistical studies were performed for the pretreatment process and the results indicated that the model and experiments were reliable and significant. The optimal conditions were found to be a temperature of approximately $42.74^{\circ} \mathrm{C}$, ammonia concentration of approximately $20.93 \%$, and a reaction time of $48 \mathrm{~h}$. When the pretreatment was performed using the optimal conditions, approximately $13.91 \mathrm{~g} / \mathrm{L}$ (approximately $87.24 \%$ of the theoretical maximum) of fermentable glucose was recovered. Fermentation process using the recovered glucose yielded ethanol at approximately $83 \%$ of the theoretical maximum. The combined pretreatment of rice straw with dilute acid and aqueous ammonia was effective, and this was supported by saccharification, fermentation, XRD, and FTIR analyses.

\section{Methods}

Feedstock and chemicals

Rice straw was obtained from the Biochemical Engineering Laboratory in Kyonggi University, Suwon, Korea, and stored at $20^{\circ} \mathrm{C}$ with a relative humidity of $70 \%$ in the dark. The rice straw was ground and homogenized using a sieve of 40-60 mesh. Sulfuric acid $\left(\mathrm{H}_{2} \mathrm{SO}_{4}\right)$ and aqueous ammonia $\left(\mathrm{NH}_{3} \cdot \mathrm{H}_{2} \mathrm{O}\right)$ were 


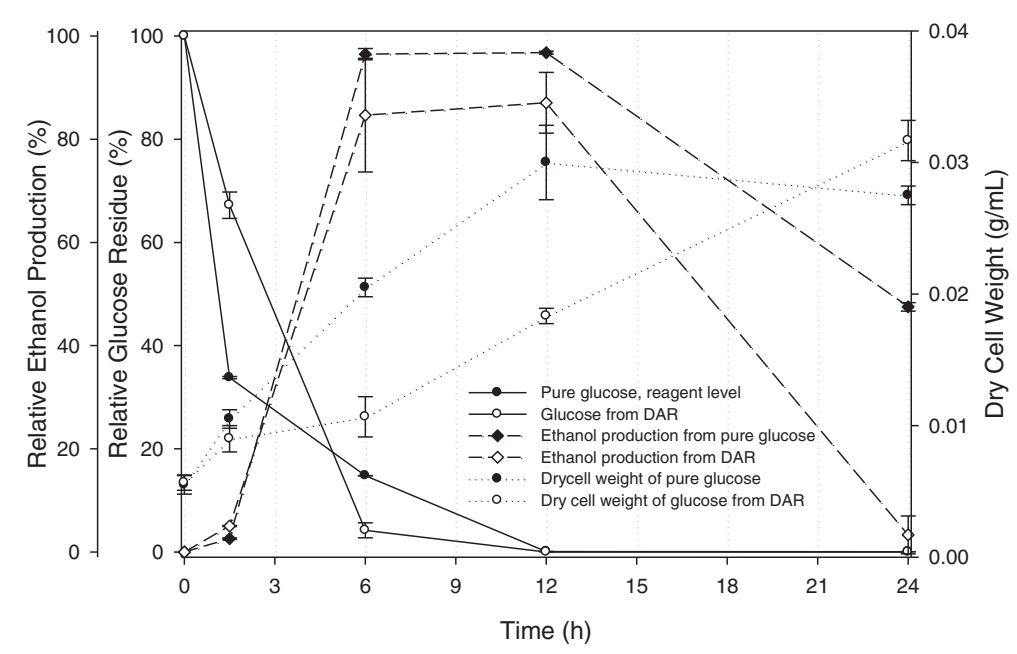

Figure $\mathbf{5}$ Results of fermentation of glucose by Saccharomyces cervisiae K35. Fermentation for ethanol production was performed at $30^{\circ} \mathrm{C}$ for $12 \mathrm{~h}$. Initial concentration of saccharified glucose was approximately $31 \mathrm{~g} / \mathrm{L}$.

utilized for the pretreatment. Both were purchased from Dea-jung Chemical, Korea.

\section{Assay method involving enzymes}

Celluclast $1.5 \mathrm{~L}$ (cellulase) from Trichoderma reesei (Novozymes, Denmark) and Novozyme188 ( $\beta$-glucosidase) from Aspergillus niger (Novozymes, Denmark) were used for the enzymatic hydrolysis of biomass. FPU for cellulase and CBU units for $\beta$-glucosidase were employed to measure the activity of enzymes. To measure FPU, enzymes were diluted at several levels. Then, $1.0 \mathrm{~mL}$ of the diluted Celluclast and $1.0 \mathrm{~mL}$ of $0.05 \mathrm{M}$ citrate buffer $(\mathrm{pH} 4.8)$ were transferred into test tubes containing $50 \mathrm{mg}$ of filter paper (Whatman No. 1, $1.1 \times 6 \mathrm{~cm}$ ). An assay reaction was performed accurately at $50^{\circ} \mathrm{C}$ for $60 \mathrm{~min}$. Thereafter, dinitrosalicylic acid (DNS) was added to stop the reaction. The tubes were transferred to a water bath kept at $100^{\circ} \mathrm{C}$, and the enzymes were deactivated for $5 \mathrm{~min}$, followed by the addition of $10 \mathrm{~mL}$ of distilled water. The colored content of the tube was analyzed using a UV spectrophotometer at $575 \mathrm{~nm}$. The $\beta$ glucosidase activity was assayed in $1.0 \mathrm{~mL}$ of a reaction mixture containing $0.1 \mathrm{~mL}$ of the diluted enzyme solution and $0.9 \mathrm{~mL}$ of $1 \mathrm{mM} p$-nitrophenyl- $\beta$-Dglucopyranoside ( $p$ NPG) in $0.05 \mathrm{M}$ citrate buffer $(\mathrm{pH} 4.8)$ at $50^{\circ} \mathrm{C}$ for $30 \mathrm{~min}$. Then, $1 \mathrm{M} \mathrm{Na}_{2} \mathrm{CO}_{3}$ solution was added to the mixture and allowed to develop a color. Later, $10 \mathrm{~mL}$ of distilled water was added and the release of $p$-nitrophenol was confirmed at $400 \mathrm{~nm}$. The activities of Celluclast and Novozyme188 were $60 \mathrm{FPU}$ and $30 \mathrm{CBU}$, respectively.

\section{Pretreatment processes of biomass}

The pretreatment of rice straw with dilute sulfuric acid was performed in an oil bath using a well-sealed tube reactor that was $1.2 \mathrm{~cm}$ in diameter and $18 \mathrm{~cm}$ in length. Preheating, reaction, and cooling were performed in the oil bath. The temperature of the preheating bath was maintained at $210^{\circ} \mathrm{C}$ for faster heat transfer whereas the cooling bath was kept at room temperature. The temperature, sulfuric acid concentration, and reaction time were similar to those reported in our previous work: $142^{\circ} \mathrm{C}, 1.21 \%$ and $11.6 \mathrm{~min}$, respectively [11]. After the pretreatment, solid-liquid separation was conducted, and the solids (rice straw) were extracted, washed, and dried. Later, the pretreatment with aqueous ammonia was carried out at $26.36-93.64^{\circ} \mathrm{C}$, ammonia concentrations of $1.54-28.45 \%$, and reaction times of 7.63-88.36 h. The agitation speed and solid-liquid ratio were $250 \mathrm{rpm}$ and 1:12, respectively. This pretreatment step was performed in a $100-\mathrm{mL}$ capped bottle. The ranges of the aforementioned parameters were determined by the fundamental experiments based on other reports [20,24]. After the pretreatment, solids separated by filtration were washed with distilled water to remove the residual ammonia and establish a neutral $\mathrm{pH}$ followed by drying at $50^{\circ} \mathrm{C}$ until the weight became constant $[25,26]$.

\section{Experimental design and statistical analysis}

In the fundamental experiment, temperature, concentration of aqueous ammonia, and reaction time were deemed to be critical factors. The experimental design was constructed using a CCD with $\alpha=\left(2^{\mathrm{n}}\right)^{1 / 4}$, and 
Table 4 Independent variables and coded values

\begin{tabular}{|c|c|c|c|c|c|c|}
\hline Factors & & -1.682 & -1 & 0 & +1 & +1.682 \\
\hline Temperature $\left({ }^{\circ} \mathrm{C}\right)$ & $\left(X_{1}\right)$ & 26.36 & 40 & 60 & 80 & 93.64 \\
\hline Concentration of aqueous ammonia $(\%, v / v)$ & $\left(X_{2}\right)$ & 1.54 & 7 & 15 & 23 & 28.45 \\
\hline Reaction time (h) & $\left(X_{3}\right)$ & 7.63 & 24 & 48 & 72 & 88.36 \\
\hline
\end{tabular}

Table 4 shows the independent variables as well as the corresponding coded values for RSM. $X_{1}, X_{2}$ and $X_{3}$ correspond to temperature, concentration of ammonia, and reaction time, respectively.

The results of 20 experiments were collated to optimize the conditions of alkaline pretreatments with aqueous ammonia. The variables were symbolized as follows:

$$
x_{i}=\left(X_{i}-X_{0}\right) / \Delta X(i=1,2,3, \ldots, j)
$$

where $x_{i}$ is the coded value of the variable $X_{i}, X_{O}$ is the independent variable real value at the center point, and $\triangle X$ is the step change value. The behavior of the system was explained by the following second-degree polynomial equation:

$$
\mathrm{y}=\beta_{0}+\Sigma \beta_{\mathrm{i}} \mathrm{X}_{\mathrm{i}}+\Sigma \beta_{\mathrm{ii}} \mathrm{X}_{\mathrm{i}}^{2}+\Sigma \beta_{\mathrm{ij}} \mathrm{X}_{\mathrm{i}} \mathrm{X}_{\mathrm{j}}
$$

where $y$ is the predicted response, $X_{i}$ and $X_{j}$ are the input variables that influence the response variable $\mathrm{Y}$, $\beta_{0}$ is the offset term, $\beta_{i}$ is the $i^{\text {th }}$ linear coefficient, $\beta_{\mathrm{ii}}$ is the quadratic coefficient, and $\beta_{\mathrm{ij}}$ is the $\mathrm{ij}^{\text {th }}$ interaction coefficient. The experimental design and the observed and predicted values of 20 experiments are presented in Table 5 . The maximum values of the solubility yield of glucose from saccharification were taken as responses of the designed experiments.

A CCD for three independent variables, each at five levels, was employed to fit a second-order polynomial model, which required 20 experiments [27,28]. The Design-Expert ${ }^{\oplus} 6.0$ package program (Stat-Ease, USA) was used for experimental design, regression analysis of data, and estimation of the coefficients of the regression equation.

\section{Saccharification and fermentation}

Enzymatic hydrolysis for enzyme digestibility was investigated according to the NREL standard procedure [12].

\begin{tabular}{|c|c|c|c|c|c|c|c|c|}
\hline Run & $\mathrm{X}_{1}$ & $\mathrm{X}_{2}$ & $x_{3}$ & Observed glucose (\%) & Predicted glucose (\%) & Residual & $95 \%$ confidence limits for mean & predicted value \\
\hline 1 & -1 & -1 & -1 & 48.17 & 43.85 & 4.32 & 35.53 & 52.17 \\
\hline 2 & +1 & -1 & -1 & 60.55 & 56.41 & 4.14 & 48.09 & 64.73 \\
\hline 3 & -1 & +1 & -1 & 62.01 & 59.43 & 2.58 & 51.11 & 67.75 \\
\hline 4 & +1 & +1 & -1 & 78.22 & 76.73 & 1.49 & 68.41 & 85.05 \\
\hline 5 & -1 & -1 & +1 & 43.32 & 43.23 & 0.09 & 34.91 & 51.55 \\
\hline 6 & +1 & -1 & +1 & 48.14 & 49.14 & -1.00 & 40.82 & 57.46 \\
\hline 7 & -1 & +1 & +1 & 78.21 & 80.77 & -2.56 & 72.45 & 89.09 \\
\hline 8 & +1 & +1 & +1 & 88.68 & 91.42 & -2.74 & 83.10 & 99.74 \\
\hline 9 & -1.682 & 0 & 0 & 55.32 & 57.18 & -1.86 & 49.26 & 65.11 \\
\hline 10 & +1.682 & 0 & 0 & 76.35 & 76.70 & -0.35 & 68.78 & 84.63 \\
\hline 11 & 0 & -1.682 & 0 & 24.46 & 28.18 & -3.72 & 20.25 & 36.10 \\
\hline 12 & 0 & +1.682 & 0 & 78.35 & 76.84 & 1.51 & 68.92 & 84.77 \\
\hline 13 & 0 & 0 & -1.682 & 58.47 & 65.15 & -6.68 & 57.22 & 73.7 \\
\hline 14 & 0 & 0 & +1.682 & 81.45 & 76.98 & 4.47 & 69.06 & 84.91 \\
\hline 15 & 0 & 0 & 0 & 77.96 & 78.14 & -0.18 & 73.99 & 82.29 \\
\hline 16 & 0 & 0 & 0 & 79.45 & 78.14 & 1.31 & 73.99 & 82.29 \\
\hline 17 & 0 & 0 & 0 & 80.98 & 78.14 & 2.84 & 73.99 & 82.29 \\
\hline 18 & 0 & 0 & 0 & 81.25 & 78.14 & 3.11 & 73.99 & 82.29 \\
\hline 19 & 0 & 0 & 0 & 78.15 & 78.14 & 0.01 & 73.99 & 82.29 \\
\hline 20 & 0 & 0 & 0 & 71.45 & 78.14 & -6.69 & 73.99 & 82.29 \\
\hline
\end{tabular}

Table 5 Design of experiment (DOE), and results of DOE and statistical predictions 
The reactions were performed at $50^{\circ} \mathrm{C}$ in $0.05 \mathrm{M}$ of citrate buffer $(\mathrm{pH} 4.8)$ at $150 \mathrm{rpm}$. Fermentation with glucose, produced by saccharification, was performed using Saccharomyces cerevisiae K35 [22,29]. The cells were inoculated with the YM broth medium and incubated at $30^{\circ} \mathrm{C}$ and $200 \mathrm{rpm}$ for $24 \mathrm{~h}$. For the main culture, $0.5 \mathrm{~mL}$ of inoculums in the main medium was prepared in $250 \mathrm{~mL}$ Erlenmeyer flasks. The main medium was $25 \mathrm{~mL}$ of distilled water containing $0.5 \mathrm{~g}$ yeast extract, 0.5 g peptone, $0.1 \mathrm{~g} \mathrm{MgSO}_{4} \cdot 7 \mathrm{H}_{2} \mathrm{O}$, and $0.1 \mathrm{~g} \mathrm{~K}_{2} \mathrm{HPO}_{4}$, to which $25 \mathrm{~mL}$ of a saccharified liquid containing $62 \mathrm{~g} / \mathrm{L}$ glucose was added. The initial $\mathrm{pH}$ and temperature of the fermentation process were kept at 5.0 and $30^{\circ} \mathrm{C}$, respectively, for $12 \mathrm{~h}$. On the completion of the fermentation process, solid-liquid separation by centrifugation was performed at $8000 \mathrm{rpm}$ for $30 \mathrm{~min}$, and the solids were separated and dried to measure the dry cell weight.

\section{Analytical methods}

Analysis of the solid biomass was performed to determine its absolute composition, according to the standard procedures of the National Renewable Energy Laboratory (NREL, USA) [30]. For acid hydrolysis, biomass was incubated with sulfuric acid $(72 \%, w / w)$ at $25^{\circ} \mathrm{C}$. After the primary hydrolysis, the solution was diluted to $4 \%$ and heated to $121^{\circ} \mathrm{C}$ in an autoclave. On cooling, the mixture was neutralized with calcium carbonate. The supernatant of the biomass composition was then analyzed by high-performance liquid chromatography (HPLC) using an Aminex HPX-87H ion exclusion column (Bio-Rad) and a refractive index detector. The HPLC conditions included a column at $50^{\circ} \mathrm{C}$, a mobile phase of $0.005 \mathrm{~N} \mathrm{H}_{2} \mathrm{SO}_{4}$, and a flow rate of $0.8 \mathrm{~mL} / \mathrm{min}$. The amount of glucose after saccharification and ethanol production yield were also measured by HPLC. All calculations of production and mass balance were performed by considering the biomass composition. This method was based on the solid biomass analysis of NREL [30]. While executing the experimental steps, the biomass was carefully manipulated to prevent weight loss.

To measure the CrI, the XRD (X'pert pro, PANanalytical, the Netherlands) analysis was performed wherein the spectra was produced by the $\theta-2 \theta$ method $[18,19]$. The XRD was operated with $45 \mathrm{kV}$ and $30 \mathrm{~mA}$ at room temperature. The anode material was $\mathrm{Cu}$ and the $\mathrm{K}-\alpha$ (irradiation) was 1.544 . The scan range was $10^{\circ}-90^{\circ}$ and the step size was $0.167^{\circ}$. The intensities of the amorphous $\left(2 \theta=18^{\circ}\right)$ and crystal $\left(2 \theta=22^{\circ}\right)$ regions, as reported by Segal et al. [22], were used to calculate $\mathrm{CrI}$ as follows:

$$
(\mathrm{CrI})=\frac{I_{22^{\circ}}-I_{18^{\circ}}}{I_{22^{\circ}}} \times 100(\%)
$$

where $I_{\theta^{\circ}}$ is intensity at the corresponding $\theta$.
An FTIR spectroscopy analysis was also performed. The transmission the FTIR spectra were obtained using the FTIR spectrometer on an ambient atmosphere bench (Perkin-Elmer, Spectrum GX). The instrument was equipped with liquid-nitrogen-cooled mercury cadmium tellurium (MCT). The resolution of the spectra was $4 \mathrm{~cm}^{-1}$, and 256 scans were included to increase the signal-to-noise ratio $[20,21]$.

\begin{abstract}
Abbreviations
CBU: Cellobiase unit; CCD: Central composite design; Crl: Crystallinity index; CV: Coefficient of variance; DAR: Dilute acid and aqueous ammonia combined pretreated rice straw; DNS: Dinitrosalicylic acid; DOE: Design of experiment; DR: Dilute-acid-pretreated rice straw; FPU: Filter paper unit; FTIR: Fourier transform infrared; HMF: Hydroxymethylfurfural; HPLC: Highperformance liquid chromatography; MCT: Mercury cadmium tellurium; NREL: National Renewable Energy Laboratory; $p$ NPG: $p$-nitrophenyl- $\beta$-Dglucopyranoside; $\mathrm{R}^{2}$ : Determination coefficient; RR: Raw rice straw; RSM: Response surface methodology; SAA: Soaking in aqueous ammonia; XMG: Xylose, mannan and galactan; XRD: X-ray diffractometry.
\end{abstract}

\section{Competing interests}

The authors declare that they have no competing interests.

\section{Authors' contributions}

SBK performed overall experiment containing statistical experiment design and wrote the manuscript. SJL, JHL and YRJ helped with the overall experiments of the pretreatment and instrumental analysis. LPT, YU and JSK advised on the fermentation process and preparation of media. CP and SWK coordinated the experimental design and reviewed the manuscript. All authors read and approved the final manuscript.

\section{Acknowledgement}

This study was supported by the Technology Development Program (309016-5) for Agriculture and Forestry from the Ministry for Food, Agriculture, Forestry and Fisheries, Republic of Korea, and Creative Allied Project (CAP) of the Korea Research Council of Fundamental Science and Technology (KRCF)/Korea Institute of Science and Technology (KIST).

\section{Author details}

${ }^{1}$ Department of Chemical and Biological Engineering, Korea University, Seoul 136-701, South Korea. ${ }^{2}$ Department of Chemical Engineering, Kyonggi University, Suwon 443-760, South Korea. ${ }^{3}$ Clean Energy Research Center, Korea Institute of Science and Technology, Seoul 136-791, South Korea. ${ }^{4}$ Department of Chemical Engineering, Kwangwoon University, Seoul 139-701, South Korea.

Received: 1 April 2013 Accepted: 26 July 2013

Published: 30 July 2013

\section{References}

1. Alvira P, Tomas-Pejo E, Ballesteros M, Negro MJ: Pretreatment technologies for an efficient bioethanol production process based on enzymatic hydrolysis: a review. Bioresour Technol 2010, 101:4851-4861.

2. Fukuda $\mathrm{H}$, Kondo A, Tamalampudi S: Bioenergy: sustainable fuels from biomass by yeast and fungal whole-cell biocatalysts. Biochem Eng J 2009, 44:2-12.

3. Hendriks ATWM, Zeeman G: Pretreatments to enhance the digestibility of lignocellulosic biomass. Bioresour Technol 2009, 100:10-18.

4. Knocke C, Vogt J: Biofuels-challenges \& chances: how biofuel development can benefit from advanced process technology. Eng Life Sci 2009, 2:96-99.

5. Sangarunlert W, Piumsomboon P, Ngamprasertsith S: Furfural production by acid hydrolysis and supercritical carbon dioxide extraction form rice husk. Korean J Chem Eng 2007, 24:936-941.

6. Kaushal $\mathrm{P}$, Abedi J: A simplified model for biomass pyrolysis in a fluidized bed reactor. J Ind Eng Chem 2010, 16:748-755.

7. Tong $X, M a Y, L i$ Y: Biomass into chemicals: conversion of sugars to furan derivatives by catalytic processes. Appl Catal A-Gen 2010, 385:1-13. 
8. Kim TH, Taylor F, Hicks KB: Bioethanol production from barley hull using SAA (soaking in aqueous ammonia) pretreatment. Bioresour Technol 2008, 99:5694-5702

9. Hu Z, Wang $Y$, Wen Z: Alkali $(\mathrm{NaOH})$ pretreatment of switchgrass by radio frequency-based dielectric heating. Appl Biochem Biotechnol 2008, 148:71-81.

10. Zhu L, O'Dwyer JP, Chang VS, Granda CB, Holtzapple MT: Structural feature affecting biomass enzymatic digestibility. Biotechnol Technol 2008, 99:3817-3728

11. Kim SB, Lee SJ, Jang EJ, Han SO, Park C, Kim SW: Sugar recovery from rice straw by dilute acid pretreatment. J Ind Eng Chem 2012, 18:183-187.

12. Lee JH, Lim SL, Song YS, Kang SW, Park C, Kim SW: Optimization of culture medium for lactosucrose (4G- $\beta$-D-Galactosylsucrosw) production by Sterigmatomyces elviae mutant using statistical analysis. J Microbiol Biotechnol 2007, 17:1996-2004.

13. Jung KW, Kim DH, Kim HW, Shin HS: Optimization of combined (acid + thermal) pretreatment for fermentative hydrogen production from Laminaria japonica using response surface methodology (RSM). Int J Hydrog Energy 2011, 36:9626-9631.

14. Jeong GT, Park DH: Response surface methodological approach for optimization of enzymatic synthesis of sorbitan methacrylate. Enzyme Microb Technol 2006, 39:381-386.

15. Ko JK, Bak JS, Jung MW, Lee HJ, Choi I, Kim TH, Kim KH: Ethanol production from rice straw using optimized aqueous-ammonia soaking pretreatment and simultaneous saccharification and fermentation processes. Bioresour Technol 2009, 100:4374-4380.

16. Chen W, Pen B, Yu C, Hwang W: Pretreatment efficiency and structural characterization of rice straw by an integrated process of dilute-acid and steam explosion for bioethanol production. Bioresour Technol 2011, 102:2916-2924.

17. Kim J, Kim KS, Lee J, Park SM, Cho H, Park JC, Kim JS: Two-stage pretreatment of rice straw using aqueous ammonia and dilute acid. Bioresour Technol 2011, 102:8992-8999.

18. Segal L, Creely JJ, Martin AE, Conrad CM: An empirical method for estimating the degree of crystallinity of native cellulose using the X-ray diffractometer. Text Res J 1959, 29:786-794.

19. Fan $L T$, Lee $Y H$, Beardmore DH: Mechanism of the enzymatic hydrolysis of cellulose: effects of major structural features of cellulose on enzymatic hydrolysis. Biotechnol Bioeng 1980, 22:177-199.

20. Kim TH, Kim JS, Sunwoo C, Lee YY: Pretreatment of corn stover aqueous ammonia. Bioresour Technol 2003, 90:39-47.

21. Sun RC, Sun XF: Structural and thermal characterization of acetylated rice, wheat, rye and barley straws and poplar wood fibre. Ind Crop Prod 2002, 16:225-235.

22. Lee H, Cho DH, Kim YH, Shin SJ, Kim SB, Han SO, Lee J, Kim SW, Park C: Tolerance of Saccharomyces cerevisiae K35 to lignocellulose-derived inhibitory compounds. Biotechnol Bioprocess Eng 2011, 16:755-760.

23. Klinke $H B$, Thomsen $A B$, Ahring BK: Inhibition of ethanol-producing yeast and bacteria by degradation products produced during pre-treatment of biomass. Appl Microbiol Biotechnol 2004, 66:10-26.

24. Yoo CG, Nghiem NP, Hicks KB, Kim TH: Pretreatment of corn stover using low moisture anhydrous ammonia (LMAA) process. Bioresour Technol 2011, 102:10028-10034.

25. Wei GY, Wa G, Jin IH, Yoo SY, Lee JH, Chung CH, Lee JW: Pretreatment and saccharification of rice hulls for the production of fermentable sugars. Biotechnol Bioproc Eng 2009, 14:828-834.

26. Yoon HH: Pretreatment of lignocelluosic biomass by autohydrolysis and aqueous ammonia percolation. Korean J Chem Eng 1998, 15:631-636.

27. Yoo CG, Lee CW, Kim TH: Optimization of two-stage fractionation process for lignocellulosic biomass using response surface methodology (RSM). Biomass Bioenerg 2011, 35:4901-4909.
28. Wiboon RN, Poonsuk P: Optimization of furfural production form hemicellulose extracted from delignified palm pressed fiber using a two-stage process. Carbohydr Res 2011, 346:103-110.

29. Kim TG, Kim K: The construction of a stable starch-fermenting yeast strain using genetic engineering and rare-mating. Appl Biochem Biotechnol 1996, 59:39-51.

30. Sluiter A, Hames B, Ruiz R, Scarlata C, Sluiter J, Templeton D, Crocker D: Determination of structural carbohydrates and lignin in biomass. NREL 2012, NREL/TP-510-42618, [http://www.nrel.gov/biomass/ analytical_procedures.html].

doi:10.1186/1754-6834-6-109

Cite this article as: Kim et al:: Pretreatment of rice straw with combined process using dilute sulfuric acid and aqueous ammonia. Biotechnology for Biofuels 2013 6:109.

\section{Submit your next manuscript to BioMed Central and take full advantage of:}

- Convenient online submission

- Thorough peer review

- No space constraints or color figure charges

- Immediate publication on acceptance

- Inclusion in PubMed, CAS, Scopus and Google Scholar

- Research which is freely available for redistribution
C Biomed Central 